\title{
Speaking with Migrant Women Health Care Aides: On Marketing and Making Sense of Caregiving in Canada
}

\author{
Gail McCabe
}

\begin{abstract}
Abatract
The objective of this resenrch was to explore the life-world of migrant women health care aides, focusing on their own subjective understandings of caregioing and the market for care in Canada. Qualitative intervicus ranging in length from one to three hours produced snapshots of the social and cultural fractures endemic to the migration and resettlement process. I argue that the women's caregiving proctice is an appect of an ethics of care that allows for moments of empowerment and resistance to an oppressive social context shaped by a matrix of race, class and gender hierarchies.
\end{abstract}

\section{Prteis}

Lebut de cette recherche est d'examiner le monde et la vie des immigrantes aidessoignantes, en concentrant notre attention sur leur propre compréhension subjective des soins de santé et du marché des soins de santé au Canada. Des entreoues d contenu qualitatif d' une longueur d'entre une et trois heures ont foumi un echentillonnage des fractures sociales et culturelles associles de façon endemique au processus de migration et de reinstallation. Je developpe une argumentation salon laquelle la pratique $f-$ minine des soins de sante est une frcette d'une thique globale des soins qui autorise une prise de pouvoir et la resistance duncontextesocial oppresseur, lui-meme faconne dans le moule de la hiérarchie des races, des classes, et des sexes.

Recently, Ihave had achance to observe migrant women health care workers while caring formy own father who was going through a terminal illness. It seemed to me that without the loyalty, dedication and expertise of the many

Gail McCabe is a Ph.D. candidate in the Department of Soctology, York University, Toronto, Canada. women who came and supported us and shared in the nursing, we would not have persevered. Through their caregiving, we were able to realize our goal: that our father should die in the comfort of his ownhome with his family and friends around him. As an aspect of my own professional practice as a rehab counsellor, I know that caregiving for strangers with the same loving demeanour usually reserved for family members culls up huge resources of energy, skill and professionalism. As part of the feminist project of bringing women's history in from the margins, I want to learn more about the lives and the labour migration of these women. I want to understand how they managed to leave their own children, partners and kinship networks behind in order to care for strangers.

In this paper, I report on qualitative interviews with four migrant women health care aides. I explore their subjective understandings of the Canadian market for care and how they make sense of their work. I found that for these women; the concept of 'stranger' was mediated through their respective cultural values, so that 'caregiving for strangers' was a normative aspect of an ethical practice, a communal practice that did not differentiate between family and strangers. By integrating an ethics of care in their lives and in their professional practice, I argue that these women were able to generate experiences of power and resistance within an oppressive social context.

\section{Situating My "Selves" in the Project}

During the time of my father's illness, there was one Filipina woman who came to help us themost. She was a very generous person with her time and her professional practice, and we became friends. When she got married, she invited all of us to her wedding, including those caregivers who were not scheduled to support my father. When we arrived at the wedding, we found that we had been given a place of honour, and that several women friends of our caregiver had been designated to ensure our comfort. Our glasses were kept full and we were accorded all the respect of highly privileged guests. Ibecame conscious all at once, that we were privileged, and perhaps we were the only ones who were not aware of our privileged status.

As white, middle-class people being supported by migrant women caregivers, we were the "employers" even though we had never thought reflexively about our roles of how our actions were perpetuating a particular system or set of relations. This I would attribute to the Western hegemonic ideology of a classless society. Beyond that, in recognizing and acknowledging my privileged location, I now felt pretty much stratified within that location and helpless to effect change. So I find myself intimately involved in the research process as both researcher and participant, as one piece of dialectical configuration, the stranger/employer/ researcher layered up with the caregiver/migrant worker/subject.

As a social researcher, I want to ensure that the meanings and explanations arising from $m y$ investigations are those of the participants. Yet the potential for conflating my own subjective experiences and notions with those of the participants is particularly possible from the dual position of researcher and participant. Nevertheless, the feminist perspective that informs my research accounts for the duality of my position as a valued and meaningful location from which to research. The expectation is that I will continually acknowledge and account for my own subjective "thoughts and experiences ... as another layer of data for investigation" at 
every stage of the research (Kirby and McKenna 1989, 32).

Moreover, the process of working through the dual location as participant and researcher has been empowering. My role as participant allows for insights that could be acted upon in a research framework, and my role as researcher has led me to a clearer recognition of my own social location within a global framework. So my sense ofbeing locked into my stratified position as "white middle-class privileged employer" has to some extent been abrogated by my efforts to use my privilege to amplify he voices of migrant women caregivers; to bring the socially constructed matrix of race, class and gender as it defines our lived experiences into stark relief (Jhappan 1996, 15-30).

\section{Situating the Participants in the}

Research

I am providing a brief introduction of the women in order to ground their commentary in this paper.1 I am acquainted with all four of these women; two of them were palliative caregivers for my father; the other two were colleagues at a not-forprofit, private social service agency serving people with acquired brain injury (ABI). Prior to this study, I had interacted with these women mainly during the course of our work together.

Caitlin is a 36-year-old woman of Filipina origin. She came to Canada in 1990 under the "Live-in Caregiver Programme." She now works as a home health-care aide for elderly and palliative care clients. In 1978, Donna, a 37year-old woman of Jamaican origin, came to Canada as a landed immigrant sponsored by an uncle. She spent almost four years as a caregiver and housekeeper for his family, living in a room in the basement of his home. Donna is now a home health-care aide for the elderly and palliative care clients. Iris, a 49-year-old woman from Sri Lanka, immigrated to Canada in May of 1995. She is working part-time as a rehab counsellor. Gerry emigrated from Ghana in 1978 under the family reunification program. Gerry is also employed part-time as a rehab counsel

Refuge, Vol. 17, No.1 (February 1998) lor. With the exception ofIris, all of the women are highly educated, having attained either a university degree or college diploma.

\section{An Ethics of Care in Practice}

For the most part, I found that the lived experiences of these women were de fined by their commitment to an ethics of care. Moreover, I contend that they take up this moral and philosophical position both as an ethical and practical standpoint and as a mode of resistance. Such an explanation is subject to critiques of gender essentialism, stereotyping, "reification of femininity," ethnocentrism, and romanticism (Deveaux 1995, 116). However, there has been a great deal of scholarly work hat speaks to those critiques and provides analytical frameworks for integrating an ethics of care with a discourse of rights and justice that is applicable to labour migration flows, citizenship rights and the materialization of the "global citizen.,,2

Care can be defined as the process through which the species seek to maintain themselves and their environment (Tronto 1995, 142). As such, care is basic to social relations through the shaping of humans as embodied agents. An ethics of care then implies a set of values or moral principles that apply to a set of

life-sustaining practices. An ethics of

care is gender neutral, and not biologically determined (Deveaux 1995, 11516). The defining tenet of a perspective of care is that "persons are relational and interdependent" as opposed to the individual, autonomous agents that are central to a rights or justice-based ethics (Held 1995, 132). Underlying the notion of an ethics of care is the belief that" civilization depends on a culture of sharing and caring; a culture of caring does not depend on civilization" (Adelman 1996, 17).

Deveaux $(1994,177)$ suggests that critiques of an ethics of care reflect" a failure to recognize the nature and scope of care as both an ethic and a set of practices." By overlooking the ethical dimensions of caregivingpractice, "social and political inequalities" (ibid., 117) endemic to the gendered polarization of care are reproduced. Moreover, caregiving can be identified in social institutions beyond the social reproductive work of women. For example, Adelman (1996, 8) figures the Welfare State as the "institutionalization of care" through the "common civic understanding" of "capital, government and labour." As such, it represents the integration of an ethics of care with an ethics of rights and justice. The Canada Health Act is one exemplar of such an ethical position enshrined in law; the universal need for care supersedes the notion of the individual's ability to pay. From that perspective, the ongoing dismantling of the Welfare State can be read as "a throw-back to primitivism" just because caregiving is radically devalued in the ensuing structural adjustments (ibid.,

\section{The Canadian Market for Care}

Research outcomes and analysis have indicated that the Canadian market for care has been shaped largely by discourses that devalue women's work and commodify migrant women caregivers. Here, I examine to what extent an ethics of care also infuses the Canadian market for caregivers and to what extent the women themselves, bring an ethics ofcare to the market: How do they define their experiences within the Canadian market for care? Does an ethics of care enter consciously into their caregiving practice? How do they explain care giving for strangers and how can their practice be read as resistance to their oppressive social location within the new global economy?

Migration to Canada has proven to be a response to innumerable structural pulls, pushes, and pressures, so that there is no doubt that the choices of migrant women are severely constrained through the process. Still, I note that the choice to market caregiving in Canada is differentially experienced depending on the women's individual life circumstances and the degree to which they are able to exercise selfagency. There seems no doubt that the choice of Canada as a host country is dependent, in large part, on the global perception of Canada as a country of 
human rights and justice integrated with a vision of caring. While these perceptions may be the result of deceptive recruitment practices and advertising, they are also informed by the existence of Canada's "sccial safety net," the "institutionalization of [an ethics of] care" (Adelman 1996, 8).

All of the women I interviewed expreseed a belief that Canada was a caring place and that belief mitigated their choice to come to Canada. Iris' migration can be understood as an act of selfagency and liberation from a more oppressive envirconment:

In the Asian culture, it is very hard to be separated or divorced. Women have little opportunity to go out by themselves and cannot stay out long or late at night. My husband had been very abusive, so I had to leave him and so I went to my family in England. Then I came on to Canada to be with my children. ... I love Canada because here there is freedom.

Donna stated that "it was much easier to go to Canada than any other place," and she believed that there would be good opportunities for a variety of experiences as well as employment. It does seem that in 1978, the year of her immigration, Canada had a relatively "open door" policy for people from the Caribbean. Granted, such policies are now falling victim to neo-conservative agendas and structural adjustment policies of the new global economy. Still, it can be argued that there was a Canadian vision that encompassed a culture of caring, and it was that vision that motivated Donna's migration. Although she was disillusioned by the need to live "from paycheck to paycheck," and the overt and systemic racism she has experienced, she still affirmed that Canada is "home" now.

Caitlin mentioned the potential for education as a positive attraction to Canida. She also believed there were many opportunities to practice in the health care sphere.

Everywhere they said Canada had the best health care. I mean I wanted to be a doctor, but my mom said because of low income we could not afford it. I was working as a midwife with a low income. I was fascinated. In Canada, they said you could study by yourself.

Caitlin recognized the Canadian'social safety net' as a huge benefit: "In the Philippines, if you have a house, you don't have as much expenses ... but when you get old or sick, it is hard, but in Canada, you will do okay. The health care system is so good." Again, the Canada Health Act can be interpreted as an ethics of care institutionalized in practice. Itmight be argued that Caitlin has chosen Canada as a permanent venue because of that vision of caring and her application for citizenship can be understood as the shaping of her life through self-agency.

Gerry came to Canada to join her husband who was doing graduate work at a Canadian university. Educational opportunities can also be interpreted as an ethics of care institutionalized practice. Like Donna, Gerry was disillusioned with the Canadian promise of care, justiceand humanrights. It seemed that racism has had a devastating effect on her "satisfaction with Canada" and her experience of herself as an independent agent.

People tend to stereotype Africans. They really thought we lived in trees and there is a naivete; they think Africa is one country. If I had learned about Caradian geography, it seemed strange that Canadians knew so little about Africa. ... I find that there is less positive human interaction and more differential treatment between people. Ghana is more community-based; we treat people

like humans; so Ghana is home.

All the women had negative experiences of racism, although they conceptualized them differently. For example, both Iris and Caitlin denied racist experiences. Yet, their anecdotal reports seemed to contradict their denials. Caitlin seemed too polite to talk about racism when asked directly, but she recounted interactions with her Canadian employers that were indicative of racial stereotyping and oppression. In Iris'scase, the recognition of racism was projected onto her co-workers: “Yes, I think there is racism, but I personally have not experienced it. I have only heard about it. The black women here, especially, believe that they are experiencing racism." Several interpretations are possible. Either Iris has been most fortunate and has not experienced the well-documented Canadian systemic racism or in her pleasure at having escaped sexist oppression in Sri Lanka, she was not yet ready to examine her refuge for othermodes of oppressivesignification. Then again, her reports might be indicative of hierarchies of colour since it was the "black" women who are reporting racist oppression.

I understand the social stratification by race, gender and class and other such categories to be the antithesis of anethics of care, for such symbolic signifiers are the basis for oppressive socially constructed hierarchies of privilege and power. Quite clearly, the reports of the women indicated the presence of such hierarchies in Canada and the constraints such structural impediments imposed on their self-agency. On balance, Canada also offered elements of an institutionalized ethics of care that apparently facilitated acts of selfagency in the lives of these particular women.

\section{Caregiving as Agency and Resistance}

All the women indicated that caregiving was their chosen profession, although they might aspire to practice at some different level. For example, Donna indicated that she wanted to "docounselling from my church" but that she couldn' $t$ "seetraining for it now or in the future." This she attributed to a poor financial outlook and the high stress levels of a double day of work. Nevertheless, in defining care in relation to her present position, she said with great gusto and straight from the heart, "Oh, you do it, because you love it." Her primary concern was for the comfort of her clients, their personal hygiene, nutrition and environment.

Caitlin wanted to "be a doctor, butmy mom said because of low income we could not afford it." Instead she trained as a midwife and now practices as a 
health care aide. She has continued her education, augmenting her professional skills and theoretical knowledge with numerous college courses. Some of these were self-initiated; others were requisites of her agency and paid for by them. In describing her caregiving role, she said, "1 love to take care of people. It is voluntary, you do it from the heart [she is very sincere and thumps her chest over her heart]. It is sharing yourself and your own abilities."

For Iris, "nursing was [a life-long] dream." She expressed a high level of satisfaction with her work, her chief problem being co-workers who did not seem to share her concern for client welfare:

You know with these people, it is a tragedy because they had established lives before their accidents. I also feel great sympathy for their families; even they can't keep them. And I really love to do it, care for them and then you are helping their families too.

Although Gerry had worked in a business function for the Ministry of Finance, and as a teacher in Ghana, she stated quite clearly thatcaregiving was her first choice:

I like doing caregiving ... When I make other people happy, than I feel good myself. I would rather do caregiving then any of the other things I have tried. It's part of my personality. I did some palliative care and there was a lot of satisfaction taking care of the client; but I was happy when her suffering was over. It's a good way to make a living.

It follows from the discussion and the description of their work that these particularwomen see themselves as health care professionals and professional caregivers. They are doing an essential job and they experience a high degree of satisfaction in the process. Although they might wish for better remuneration, a higher standard of living or more equitable conditions in the workplace, they were unlikely to choose other types of work. In defining care, it seemed apparent that the women understood care not only as a practice but also as an ethi cal position. Although Gerry was the only one who actually spoke in terms of an ethical stance, the others did express the notion of care as a fundamental necessity of life to be provided on the basis of need rather than the ability to pay. Moreover, all but Iris defined care as a function of community, interdependence and relationship. Iris defined" taking care of other people [as] a blessing; it's love."

At the outset of this paper, I defined a dialectical tension that evolved from the social locations of the caregiver / migrant worker and the stranger / employer. As I conducted the interviews, it struck me that I had made this distinction out of my own North American cultural context where an ethics of rights, "rugged individualism," and autonomy take precedence. None of the women I interviewed differentiated between caring for strangers and caring for family, although they recognized the instrumental contract in their work. Moreover, they tended to express their practice for strangers in terms of cultural norms that included valuing humanity and respect for the sick and elderly. For example, Gerry described caregiving as a normative practice in Ghana:

I like to do caregiving. It's something we do at home that is a norm. You rely on family and community. My mom would feed people in the neighbourhood who were in need. It was not a matter of charity; it was an interdependence that we had; the way we were raised was to be compassionate and caring.

Likewise, Donna's descriptions of Jamaica are indicative of a communal system for ensuring that individuals are cared for:

In Jamaica, you depend on each other. It is just the way it is done; you take care of the elderly and sick. It doesn't matter if you know them or not; it's just the same. I know of one old lady who lives in her home and everyone in the village drops by and does something for her. It's the only way to make out because we don't have old folk's homes or nursing homes anyway.
According to Caitlin, there were also no" old folk's homes" in the Philippines either. The sick and elderly are taken care of "voluntarily, from the heart, as part of community." Again, this was apparently a normative practice, as the needy did not have to askfor help; it was provided. Although Iris did not link her caregiving practice to cultural norms in Sri Lanka, she did state that she also did not differentiate between caring for strangers or family: "There is no difference between strangers and family. It's the same thing. I want to do care giving and I really like my clients."

I would argue that the ways the women described and practiced caregiving were indicative of their understanding that care giving is a set of practices underpinned by a set of ethical principles. Practices and ethics were informed by the principle that all humans need caring and care should be provided as a function of human interdependence. Caregiving was an act of selfagency demonstrating membership, participation and respect for community obligations. For these women, the community encompassed all human beings, including those that exploited and oppressed them. On numerous occasions, as a participant observer, I witnessed clients denigrating these women on the basis of their race, colour and ethnic origin. What was most salient in these episodes was not the abuse, but the way the women chose to deal with it. They rarely followed through with institutional "policy of responding" which entailed confrontation, social disapproval and correction. They simply did not believe that such policies were ethical or effective. Instead, they would carryon with their care giving, in the same thoughtful, attentive manner as if no hateful slurs had

been expressed. It seemed to me that they were empowered by their salience. At any rate, the clients were often reduced to tears, apologies and self-recrimination.

So what lessons of resistance do these four migrant women health care workers have for us? I would say that care giving can be read as resistance 
when it allows for empowering moments in an oppressive social situation as the result of a self-conscious agency. When these empowering moments are integrated within a structure that is defined by its overwhelming oppressiveness and the subject is not overwhelmed, then that is resistance.

Rutman (1996, 90) reports on research workshops where "women caregivers explored the experience of 'power' through their care giving," and defined the possibilities for experiencing moments of empowerment as well as moments of powerlessness in their practice. I note that the opportunities for empowering moments identified in his workshops were congruent with those identified by the women I interviewed. Moments of empowerment were experienced as respect from clients and their

families for their knowledge, skills and

opinions as professional caregivers as well as from a sense of self-worth derived from providing a benefit to clients and families (ibid., 102). Consider, for example, Caitlin's description of developing working relationships with clients and families:

... they think you don't know what you are [doing] ... maybe because I am so small [she is under 5 feet]. But after you work with them, and you insist on doing things the right way [utilizing skills acquired through education and practice], they slowly begin to see that you know your job and

they respect you [as a professional].

This is relayed with a small, satisfied chuckle as if to say that although she is small and her position may be devalued, she has prevailed because of her intrinsic worth and value.

Iris mentioned experiences of persona independence, strength and satisfaction derived directly fromherjob: "I love to do it. You do your job well and you get paid for it, and you know that you are caring for other people [when] their own families can't..." At several points in the interview, Iris mentioned the work place culture as the strongest challenge in her caregiving practice. Although she herself was quiet and unprepossessing, apparently her col leagues were not. That Iris went quietly on about her business as she defined it rather than at the dictates of others was an act of resistance. It was apparent that she also gained in confidence and strength by achieving her goals and objectives in the face of negative feedback and strong opposition from colleagues.

Congruent with the experience of other newcomers, the women seemed greatly empowered by their ability to contribute to families and communities back home, and they had strong hopes that their work would fashion a life opportunity for their children here in Canada. Thei understanding of their experiences resonated through Gerry's analysis of he double day of work: "It's not hard, not hard forme. I am a woman and I accept whaU have todo." This was said without bitterness or regret. She conveyed tome throughout, in her sense of strong satisfaction and pride in her work, her achievements and her abilities.

Although the chances and choices of these women were, to a great degree, shaped by a matrix of race, class and gender hierarchies and the structural constraints of domination and legitimation, they apparently did practice an ethics of care that allowed for empowering moments. And even though their daily experience was one of grinding poverty, social stratification, racism, isolation, lienation and fragmentation, insofar as they experienced a sense of their own powerful self-agency through their caregiving and their ethical practice, they successfully resisted an oppressive social context. II

Notes

A full profile of demographic information and variables covered in the interviews for each participant is available on request therefore.

2. A full exploration oHhis body of work an the critical response to it goes beyond the scope of this paper. My goal here is to distinguish an ethics of care as both an ethical standpoint and a set of practices that can encompass not only women's traditional reproductive labour but other forms of caregiving as well.
References

Adelman, Howard. 1996. "The Death and Rebirth of the Civil Society or The Wisdom of the Alien Other on a Global Civilization." Unpublished draft for presentation at Conference on Devolution of Settlement University, Toronto, February 16-18, 1996. Deveaux, Monique. 1995. "Shifting Paradigms: Theorizing Care and Justice in Political Theory." Hypatia 10, no. 2 (Spring): 115-

Held, Virginia. 1995. "The Meshing of Care and Justice." Hypatia 10, no. 2 (Spring) 12832

Jhappan, Radha. 1996. "Post-Modem Race and Gender Essentialism or a Post-Mortem of Scholarship." Studies in Political Economy 51 (Fall).

Kirby, Sandra L., and Kate McKenna. 1989. Experience, Research, Social Change: Research from the Margins. Toronto: Garamond Press.

Rutman, Deborah. 1996. "Care giving as Women's Work: Women's Experiences of Powerfulness and Powerlessness as Caregivers." Qualitative Health Research 6, no. 1 (February): 90-111.

Tronto, Joan. 1995. "Care as a Basis for Radical Political Judgments." Hypatia 10, no. 2 (Spring): 141-49. a

\section{Refuge \\ Canada's Periodical on Refugees}

Publisf1ed\$ix tirne\$aye,ar by the Centre for Refugee Studies, York University, Toronto.

A vailable.from:

Centre for Refugee Studjes

Yod $<$ trrdversity Suite 333, York

Lanes 4700 Keele St. Toronto

QNCanadaM3J IPS Fax: (416)

736-5837 Email:

refuge@yorku.ca

http://WWW.yorku.ca/researchJcrs 